\title{
BMJ Open Phase-out of smallpox vaccination and the female/male HIV-1 prevalence ratio: an ecological study from Guinea-Bissau
}

\author{
Andreas Rieckmann, ${ }^{1,2,3}$ Marie Villumsen (D) , ${ }^{4}$ Bo Langhoff Hønge,, 6 \\ Signe Sørup, ${ }^{1,2,7}$ Amabelia Rodrigues, ${ }^{6}$ Zacarias Jose da Silva, ${ }^{8}$ Hilton Whittle, ${ }^{9}$ \\ Christine Benn (iD , ${ }^{1,2}$ Peter Aaby ${ }^{6}$
}

To cite: Rieckmann A, Villumsen $\mathrm{M}, \mathrm{H} ø$ nge $\mathrm{BL}$, et al. Phase-out of smallpox vaccination and the female/ male HIV-1 prevalence ratio: an ecological study from Guinea-Bissau. BMJ Open 2019;9:e031415. doi:10.1136/ bmjopen-2019-031415

- Prepublication history and additional material for this paper are available online. To view please visit the journal (http:// dx.doi.org/10.1136/bmjopen2019-031415).

Received 07 May 2019

Revised 06 September 2019

Accepted 17 September 2019

Check for updates

(C) Author(s) (or their employer(s)) 2019. Re-use permitted under CC BY-NC. No commercial re-use. See rights and permissions. Published by BMJ.

For numbered affiliations see end of article.

Correspondence to Dr Andreas Rieckmann; anri@ssi.dk

\section{ABSTRACT}

Objective In Guinea-Bissau, West Africa, we observed that having a smallpox vaccination scar was associated with lower HIV-1 prevalence, more strongly for women than men. If this represents a causal effect, the female/male HIV-1 prevalence ratio would increase for birth cohorts no longer receiving smallpox vaccination due to the phase-out of this vaccine. Design An ecological design using HIV surveys and information about smallpox vaccination coverage. Setting Urban and rural Guinea-Bissau.

Participants Participants in HIV surveys were grouped into an age group with decreasing smallpox vaccination coverage (15-34 years) and an age group with steady smallpox vaccination coverage ( $\geq 35$ years).

Interventions The exposure of interest was the phase-out of the smallpox vaccine in Guinea-Bissau.

Primary and secondary outcome measures HIV-1 prevalence.

Results At both sites, the female/male HIV-1 prevalence ratio increased by calendar time for the age group with decreasing smallpox vaccination coverage; the combined female/male HIV-1 prevalence ratio among people aged $15-34$ years was 1.00 (95\% Cl 0.17 to 5.99$)$ in $1987-1990,1.16$ (95\% Cl 0.69 to 1.93) in 1996-1997, $2.32(95 \% \mathrm{Cl} 1.51$ to 3.56$)$ in $2006-2007$ ( $p$ value for no trend=0.04). There was no increase in the female-to-male HIV-1 prevalence ratio for the age group $>35$ years with steady smallpox vaccination coverage; 1.93 (95\% Cl 0.40 to 9.25$)$ in $1987-1990,1.32$ (95\% Cl 0.83 to 2.10$)$ in 1996-1997, 0.81 (95\% Cl 0.56 to 1.16) in 2006-2007 (p value for no trend=0.07).

Conclusions Thus, data was compatible with the deduction that the phase-out of smallpox vaccination may have increased the susceptibility to HIV-1 relatively more for women than men. Hence, phasing out smallpox vaccination may have contributed to the global increase in the female/ male HIV-1 prevalence ratio among young individuals. Due to the potential fallacies of ecological studies, the results should be interpreted carefully, and this hypothesis needs further assessment. If the hypothesis is true, studies of smallpox vaccination could inform HIV-1 vaccine research.

\section{INTRODUCTION}

Vaccination against smallpox infections was stopped globally in 1980 following the eradication of smallpox in 1977. It has been reported

\section{Strengths and limitations of this study}

- The ecological design allowed us to assess a deduction of the hypothesis: smallpox vaccination has a protective effect against HIV-1 which is stronger among women than among men.

- To increase the robustness of the results, we utilised parallel data from both urban and rural Guinea-Bissau.

- Ecological studies should be interpreted carefully as spurious associations can arise, and thus triangulation with existing studies are necessary to further assess this hypothesis.

that smallpox vaccination reduced susceptibility to unrelated infectious diseases, ${ }^{1}$ and in immunological in vitro studies, smallpox vaccination was associated with an up to fivefold reduction in C-C chemokine receptor 5 (CCR5) tropic HIV-1 replication. ${ }^{2}$ Based on vaccination scar readings in Guinea-Bissau and school health records in Denmark, we have shown that smallpox vaccination (and BCG) was associated with a lower risk of HIV-1. ${ }^{3}$ The adjusted OR for HIV-1 infection was $0.52(95 \%$ CI 0.32 to 0.84$)$ for women and 0.77 (95\% CI 0.48 to 1.24) for men. This association was stronger for women, who had received multiple smallpox vaccinations (OR of 0.18 (95\% CI, 0.05 to 0.64 )).

We hypothesised that smallpox vaccination has a stronger protective effect against HIV-1 in women than men. If this is the case, a logical deduction is that the female/male HIV-1 prevalence ratio should increase for age groups with decreasing smallpox vaccination coverage while there would be no change in the female/male HIV-1 prevalence ratio for age groups with steady smallpox vaccination coverage. By using a female/male HIV-1 prevalence ratio, we could to some extent disregard calendar time trends-such as the general spread of HIV-1 worldwide and the 
increased focus on prophylaxis and treatment-affecting both sexes and all age groups. We tested the hypothesis in two cohorts followed with sequential HIV surveys in Guinea-Bissau since the late 1980s.

\section{METHODS}

In this ecological study, we compared the changes in smallpox vaccination coverage with the change in female/ male HIV-1 prevalence ratio for the age groups that were between 15 and 34 (a decreasing smallpox vaccination coverage) and $\geq 35$ years (a steady smallpox vaccination coverage) over a 30-year period. All analyses were based on aggregated data from different sources: We used reported HIV-1 prevalence surveys in Bissau, the capital of GuineaBissau, and Caió, a rural district of Guinea-Bissau. ${ }^{45}$ We used individually-based data from a smallpox vaccination scar survey in Bissau in 2005 to model smallpox vaccination coverage at the time of the HIV-1 surveys.

\section{Patient and public involvement}

As this study was based on previously published data, ${ }^{4-6}$ neither patients or the public were involved in conducting this research.

\section{Estimates of smallpox vaccination coverage}

Smallpox vaccination typically leaves a distinct vaccination scar. We used a cohort of individuals, who had both participated in a smallpox vaccination scar survey (2005-2007) and an HIV prevalence survey (2004-2006) conducted in Bissau (previously published ${ }^{6}$ ) to model the historical changes in smallpox vaccination coverage (see below). The smallpox vaccination scar prevalence is comparable between urban and rural Guinea-Bissau. ${ }^{78}$ In the smallpox vaccination scar survey, field workers examined vaccination scars and interviewed study participants. The field workers examined the study participants' upper arms for vaccination scars and registered up to five scars. Scars were classified as BCG, smallpox vaccination or 'uncertain', based on size, colour and general appearance of the scar.

For each individual in the smallpox scar survey, we calculated the age the individual would have had in the different HIV survey years (1987, 1996, 2005 and 2016). We approximated the age-standardised smallpox vaccination coverage overall and by sex for the years 1987, 1996, 2005 and 2016 in each age group (15-34 and $\geq 35$ years) by dividing the number of individuals with a smallpox vaccination scar by the total number of individuals in each group. The '15-34 years' group was chosen as they have a declining smallpox vaccination coverage over the different HIV surveys. The ' $\geq 35$ years' group covered ages between 35 and 65 (oldest age registered) and had a steady smallpox vaccination coverage over the different HIV surveys. The smallpox vaccination coverage estimation for the age group $\geq 35$ in 2016 was changed to $\geq 45$ to ensure a steady smallpox vaccination coverage.
A small validation study based on a city register of smallpox vaccination from Bissau showed a sensitivity of $90 \%$ (95\% CI $80 \%$ to $95 \%$ ) by using smallpox scars as proxies for registered smallpox vaccinations (62 individuals had smallpox scars in community surveys out of 69 registered as smallpox vaccinated in the city register) ${ }^{7}$

\section{Estimates of female/male HIV-1 prevalence ratios}

Three HIV-1 prevalence surveys were carried out in parallel both in Bissau $(1987,1996,2006)^{4}$ and Caió (1990, 1997, 2007). ${ }^{5}$ An additional survey was carried out in Bissau in 2016. ${ }^{9}$ In these surveys of randomly selected households, all individuals aged 15 years or older were interviewed and tested for HIV provided they accepted the informed consent. In Guinea-Bissau, injection drug use is virtually non-existent, ${ }^{10}$ and blood transfusions have been screened for HIV since $1987^{4}$; thus, HIV-1 is almost exclusively sexually transmitted.

The results of the HIV-1 surveys were reported by sex and by 10 year age groups from 15 years of age. Based on these data, we constructed a dataset with the number of observed individuals by sex, age group (15-34; $\geq 35$ ) and HIV-1 status for each of the HIV surveys. The reason for the age cut-off of 35 years was that the last smallpox vaccination campaign in Guinea-Bissau was in 1975 and pre-school children were rarely vaccinated ${ }^{7}$ resulting in a decreasing smallpox vaccination among people aged 15-34 years individuals across HIV survey years. The combined estimates for 2016 were only based on Bissau, as no HIV survey had been carried out in Caió; in this survey, the age range was changed to $\geq 45$ to ensure a steady smallpox vaccination coverage.

The female/male HIV-1 prevalence ratio in two specific age groups was of interest in itself, but also, by using such as comparison, we could to some extent disregard calendar time trends such as the spread, prophylaxis and treatment of HIV-1, which would affect both sexes and all age groups.

\section{Statistical analysis}

We used R V.3.3.1 to estimate the female/male HIV-1 prevalence ratios among individuals aged 15-34 years $\geq 35$ years for each HIV survey (CIs were calculated using the 'epitools' $\mathrm{R}$ package for risk ratios). Individual level-data sets were reconstructed for the surveys based on the summary tables in refs 459 . To estimate the probability of data showing the observed trend in female/male HIV-1 prevalence by the combined HIV survey years (1987-1990, 1996-1997, 2006-2007) by chance, we fitted a logistic regression on HIV-1 status depending on HIV survey year as a linear and quadratic effect, sex and the interaction between a linear effect of HIV survey year and sex. The model was fitted separately for the individuals aged $15-34$ and $\geq 35$ years. We interpreted the $\mathrm{p}$ value for the interaction between survey year (assumed linear effect) and sex as a test for a homogeneous association between sex and a linear change in HIV-1 prevalence across survey years. 

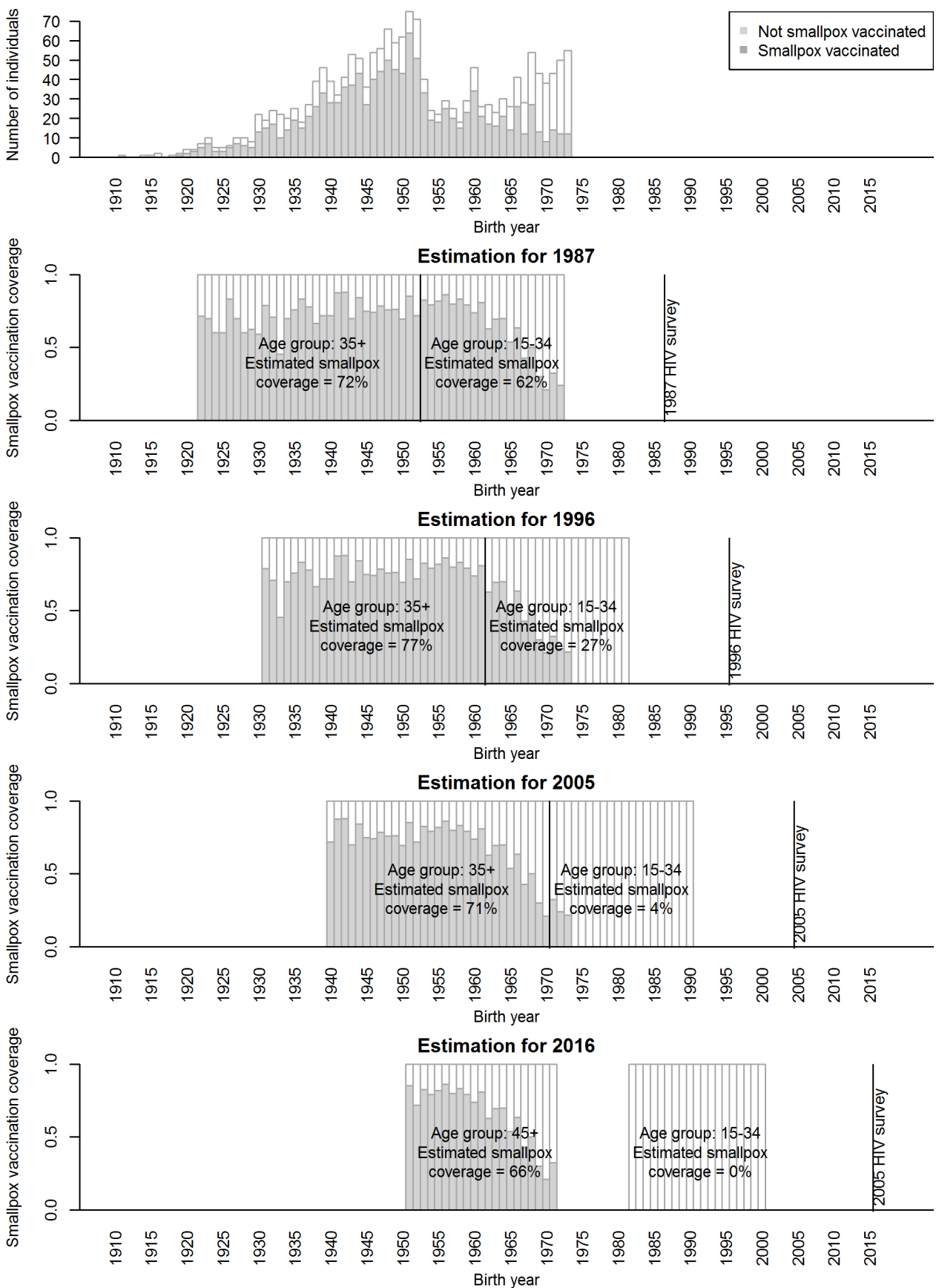

Figure 1 Estimated smallpox vaccination scar prevalence in different age groups for each sequential HIV survey. Based on data from Bissau, Guinea-Bissau, previously published. ${ }^{6}$ The estimation for the age group $\geq 35$ in 2016 was changed to $\geq 45$ to ensure a steady smallpox vaccination coverage.

\section{RESULTS}

For the age group $\geq 35$ years ( $\geq 45$ years in 2016 ), the estimated smallpox vaccination coverage was similar across all the HIV surveys (fluctuating between $66 \%$ and $77 \%$, figure 1). As expected, the smallpox vaccination coverage decreased over HIV survey years for the age group 15-34 years (from $62 \%$ in 1987 to $0 \%$ in 2016 , figure 1). There was no indication that the smallpox vaccination coverage differed between women and men (online supplementary figures 1 and 2). The general prevalence of HIV-1 among adults $\geq 15$ years of age increased from $0 \%(0 / 649)$ in 1987 to $4.6 \%(118 / 2548)$ in 2006 in Bissau and from
$0.5 \%(14 / 2770)$ in 1990 to $3.6 \%(105 / 2895)$ in 2007 in Caió. In 2016 in Bissau, the HIV-1 prevalence among adults over 15 was $4.0 \%(104 / 2601)$.

As seen in table 1, there was an increase in the female/ male HIV-1 prevalence ratio among individuals aged 15-34 years from the earliest to the latest conducted HIV surveys, the pattern being similar in Bissau and Caió. Combined, the female prevalence increased from $0.3 \%$ to $4.3 \%$ from 1987-1990 to 2006-2007, whereas the male prevalence increased from $0.3 \%$ to $1.9 \%$ in the same period. The female/male HIV-1 prevalence ratio was 1.00 (95\% CI 0.17 to 5.99 ) in 1987-1990, 1.16 (95\% CI 0.69 


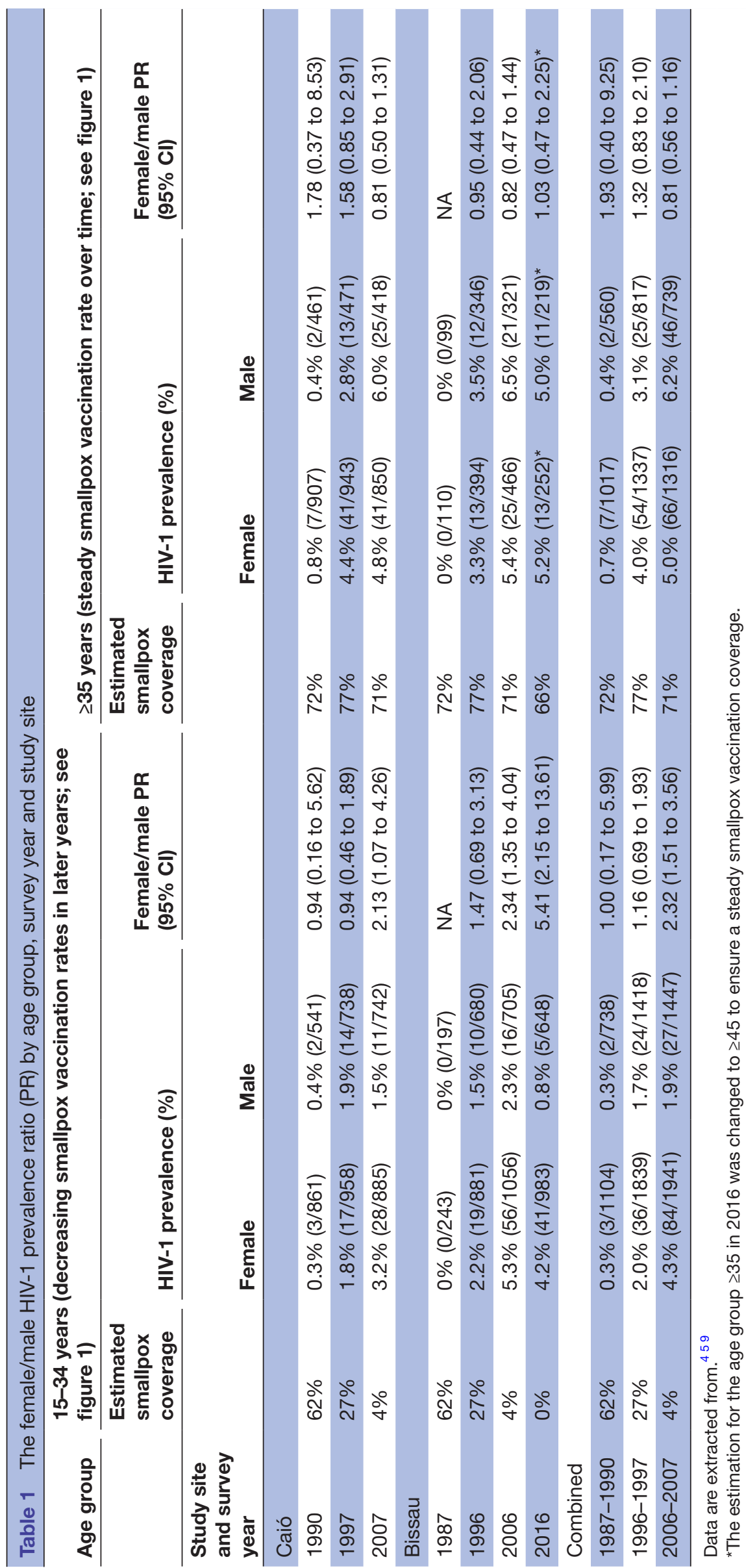




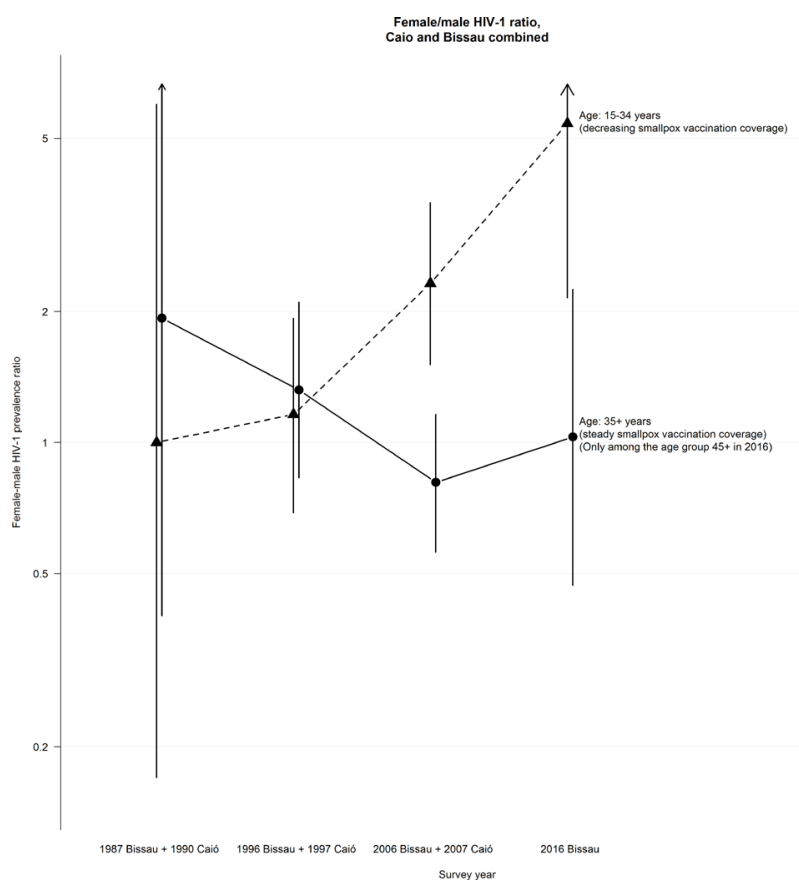

Figure 2 Female/male HIV-1 prevalence ratios, Bissau and Caió. Visualisations of estimates from table 1. Circles and triangles represent point estimates and lines represent the $95 \%$ Cls. The estimation for the age group $\geq 35$ in 2016 was only from Bissau and was changed to $\geq 45$ to ensure a steady smallpox vaccination coverage.

to 1.93 ) in $1996-1997$ and 2.32 (95\% CI 1.51 to 3.56 ) in 2006-2007. In a logistic regression, the interaction-test for a homogeneous association between sex and a linear change in HIV-1 prevalence across survey years for the individuals aged $15-34$ years gave a $p$ value of 0.04 . Latest in Bissau in 2016, the female/male HIV-1 prevalence ratio was further increased to 5.41 (95\% CI 2.15 to 13.61).

The older age group with steady smallpox vaccination coverage had no increase in the female/male HIV-1 prevalence ratio. Combined, the female prevalence increased from $0.7 \%$ to $5.0 \%$ from 1987 to 1990 to 2006-2007, whereas the male prevalence increased from $0.4 \%$ to $6.2 \%$ in the same period. Thus, the female/male HIV-1 prevalence ratios were 1.93 (95\% CI 0.40 to 9.25$)$ in 1987-1990, 1.32 (95\% CI 0.83 to 2.10 ) in 1996-1997, 0.81 (95\% CI 0.56 to 1.16 ) in 2006-2007. The test of interaction for a homogeneous association between sex and a linear change in HIV-1 prevalence across surveys gave a $\mathrm{p}$ value of 0.07 and the direction trended towards the opposite direction than for the younger age group. The female/male HIV-1 prevalence ratio was 1.03 (95\% CI 0.47 to 2.25) in 2016 in Bissau.

The combined female/male HIV-1 prevalence ratios are illustrated in figure 2. Relative to the female/male prevalence ratio among the older age group, the female/ male prevalence ratio in the 15-34 years age group increased from 0.52 (95\% CI 0.05 to 5.61 ) in 1987-1990 to 0.88 (95\% CI 0.44 to 1.75 ) in 1996-1997 to 2.88 (95\% CI 1.64 to 5.05 ) in $2006-2007$ to 5.26 (95\% CI 1.57 to
17.65) in 2016 (2016 estimates were only based on Bissau data) (ratios of ratios based on table 1 ).

\section{DISCUSSION}

As we had hypothesised, the female/male HIV-1 prevalence ratio increased for the age group 15-34 years, as the proportion with smallpox vaccination scars decreased, whereas the female/male HIV-1 prevalence ratio remained unchanged for the age group $\geq 35$ years which had a steady smallpox vaccination coverage over the HIV-1 survey years.

\section{Strengths and limitations}

This study was based on information from large HIV surveys carried out over 20-30 years in two different settings, urban and rural Guinea-Bissau. As no central smallpox vaccination register exists in Guinea-Bissau, we used smallpox vaccination scars as a proxy for the smallpox vaccination coverage. We have previously shown that smallpox scars have a sensitivity of $>90 \%$ in correctly identifying smallpox vaccinated individuals (no specificity measure available). ${ }^{7}$ Some BCG vaccination scars and accidental wounds may have been misclassified as smallpox vaccination scars, but misclassification is unlikely to be sex-differential. Potential variation in false-positive and false-negative rates of scar across surveys would likewise not be expected to be sex-differential. Participation in the HIV surveys varied only slightly across the survey years in Bissau, being $86 \%$ in 1987, $85 \%$ in 1996, $79 \%$ in 2006 and $83 \%$ in 2016; furthermore, the HIV prevalence in participants, who were easy to reach, was similar to the prevalence in those who were difficult to reach. ${ }^{49}$ Hence, differential participation in different study years is unlikely to have caused selection bias.

The ecological design enabled us to investigate a potentially important hypothesis, but the results needs to be interpreted with caution since this design can be vulnerable to misinterpretations. By using the ratio of HIV-1 prevalence between sexes and within age groups, we could to some extent disregard calendar time trends such as the spread, prophylaxis and treatment of HIV-1 affecting both sexes and all age groups.

\section{Female/male HIV-1 prevalence trends in sub-Saharan Africa}

Consistent with our finding, cross sectional surveys from Malawi, ${ }^{11}$ Zambia $^{12}$ and South Africa ${ }^{13}$ show that the birth cohorts who are too young to have been smallpox vaccinated have an increased female/male HIV prevalence compared with older birth cohorts, who are likely to have been smallpox vaccinated before the worldwide phase-out in 1980.

UNAIDS data for the female/male HIV-1 prevalence from 1985 to 2003 in Sub-Saharan Africa shows that in the age group of 15-49 years, the number of HIV-1 affected women began to increase over the number of men during the early 1990s. ${ }^{14}$ The female/male HIV-1 ratio increased at the same time as the smallpox vaccination coverage 
decreased after 1980. A multicountry study using repeated national representative demographic and health surveys on HIV prevalence in Sub-Saharan Africa during the 2000s did not find an increasing female/male HIV prevalence ratio. ${ }^{15}$ In contrast to the HIV surveys from Guinea-Bissau, where there was a clear increase in the prevalence of HIV-1, the reported HIV prevalence generally decreased between repeated surveys in other regions of Africa. ${ }^{15}$ The female/ male HIV prevalence ratio may be influenced by multiple factors, and the introduction of HIV treatment, which only took place in the late 2000s in Guinea-Bissau ${ }^{16}$ may have blurred the female/male HIV prevalence ratio trends in the 2000s surveys from Sub-Saharan Africa.

\section{Potential causes of sex differences in HIV-1}

The sex differences in the susceptibility to HIV-1 could theoretically be due to physiological, hormonal or local microbial differences, and higher prevalence of sexually transmitted diseases causing a higher male-to-female than female-to-male HIV transmission rate. ${ }^{14}$ These explanations would however not explain why young women in SubSaharan Africa did not have a higher HIV-1 prevalence than men when the HIV epidemic started. Our results showed that women and men in the age group of $<35$ years had similar HIV-1 prevalence in 1987-1990 of 0.3\% but while men's HIV-1 prevalence did not increase much in the younger age group, potentially due to more focus on availability and use of condoms over time, women's HIV-1 prevalence continued to increase (table 1). It may be that females' increased susceptibility were neutralised by the smallpox vaccination and became expressed when smallpox vaccination was stopped.

Alternative explanations for the sex-age-time pattern may be sought in social and cultural changes over time, including gender-power imbalances. ${ }^{14}$ Analyses of sexual mixing patterns from South Africa ${ }^{13}$ suggest that since young women often have sexual relations with older men, then as the prevalence of HIV-1 increases among older men the prevalence among young women will follow. We have no specific data to assess possible changes over time in the frequency of sexual relations across age groups. All ethnic groups in Guinea-Bissau has a taboo on intercourse while the mother is breast feeding for 1.5-3 years, which may have created a permissive attitude towards extramarital sexual relationships (possibly causing sexual relations between older men and younger women). We have documented such taboo on intercourse while breast feeding and a permissive attitude back to the 1980s in GuineaBissau, ${ }^{17}$ so it is clearly not a new phenomenon. While it is possible that behavioural patterns became increasingly permissive of extramarital sexual relationships in a setting with rapidly increasing urbanisation, it seems unlikely that the same change would have happened in a rural setting. We find it unlikely that the similar pattern of increasing female/male HIV-1 prevalence ratio in both an urban and a rural setting can be explained merely by changes in sexual behaviour patterns. During the study period, there may have been increased awareness and availability of condoms, but this would likely have affected the risk of acquiring HIV equally in both sexes or if anything diminished the risk in females relative to males.

The female/male HIV-1 prevalence ratio for the 15-34 years age group seems to continue to increase in Bissau with a ratio of 5.41 (95\% CI 2.15 to 13.61) in 2016 compared with 2.34 (95\% CI 1.35 to 4.04 ) in 2006, despite the prevalence of smallpox vaccination coverage for this age group was estimated to change from $4 \%$ to $0 \%$, suggests that other factors continue to affect the susceptibility of HIV-1 differently for men and women.

\section{Biological mechanisms}

The CCR5 is fundamental for establishing HIV-1 infections. ${ }^{18}$ The CCR5-delta-32 deletion confers resistance to HIV-1 by preventing the expression of the CCR5 receptor; this allele provides almost complete resistance to HIV-1 in homozygous individuals. ${ }^{18}$ A recent immunological study found that cells from smallpox vaccinated individuals had up to fivefold reduction in CCR-5 tropic HIV-1 replication in vitro, ${ }^{2}$ which supports a role of the smallpox vaccine in HIV-1 prevention through heterologous immunity. A recent study did not show an association between smallpox vaccination scar and CCR5 expression on the surface of peripheral T-lymphocytes among HIV seronegative women old enough to have had a chance of being smallpox vaccinated ${ }^{19}$; this may be due to delay between smallpox vaccination and immunological testing of more than four decades or that the smallpox-unvaccinated control group had received another immunomodulator, the $\mathrm{BCG}$ vaccine. ${ }^{20}$

In animal models, administrating smallpox vaccination via skin scarification has been demonstrated to increase the immune response and survival compared with other modes of administration..$^{21}$ Murine studies have shown that intradermal smallpox vaccination induced longlived non-recirculating CD8+skin resident T-memory cells that resided within the entire skin and protected against reinfection. ${ }^{22}$ This indicates that vaccination can spread throughout the entire epithelial surface to create a 'shield' against infection.

Smallpox vaccine may also affect the innate immune system more broadly; in a very recent study, human monocytes trained with smallpox vaccine showed significantly increased interleukin- 6 and TNF- $\alpha$ (tumor necrosis factor) production to stimulation with non-related stimuli, compared with non-trained monocytes. ${ }^{23}$

Overall, there is some immunological evidence to support that smallpox vaccination can provide crossprotection against HIV-1 infection. None of the above studies reported effects by sex, but it is plausible that an epithelial protection might be particularly protective against vaginally acquired HIV-1 infection.

\section{CONCLUSION}

Our hypothesis that the phase-out of smallpox vaccination may have increased the female/male HIV-1 
prevalence ratio was compatible with our results. This hypothesis needs further assessments to determine if the relationship is causal, and we hope other research groups will test the hypothesis and other potential explanations for the change in female-to-male HIV prevalence ratios over time in individual-based data. If more support for the hypothesis that smallpox vaccine protected females against HIV can be obtained, from epidemiological and immunological studies, it could provide important information for HIV-1 vaccine research even though it may not be possible to reintroduce the smallpox vaccine.

\section{Author affiliations}

${ }^{1}$ Bandim Health Project, OPEN, Department of Clinical Research, University of Southern Denmark/Odense University Hospital, Odense, Denmark

${ }^{2}$ Research Center for Vitamins and Vaccines (CVIVA), Bandim Health Project, Statens Serum Institut, Copenhagen, Denmark

${ }^{3}$ Section of Epidemiology, Department of Public Health, University of Copenhagen, Copenhagen, Denmark

${ }^{4}$ Center for Clinical Research and Prevention, Bispebjerg and Frederiksberg Hospital, Capital Region, Copenhagen, Denmark

${ }^{5}$ Department of Infectious Diseases, Aarhus University Hospital, Aarhus, Denmark

${ }^{6}$ Bandim Health Project, Indepth Network, Bissau, Guinea-Bissau

${ }^{7}$ Department of Clinical Epidemiology, Aarhus University, Aarhus, Denmark

${ }^{8}$ National Institute of Public Health (INASA), Bissau, Guinea-Bissau

${ }^{9}$ London School of Hygiene and Tropical Medicine, London, UK

Contributors AR and PA designed the study and drafted the manuscript. AR, MV BLH, SS, AR, ZJdS, HW, CB and PA have substantially contributed to the analysis and interpretation of the results. BLH and ZJdS designed and acquired data with regards to the original papers of which data is reanalysed in this paper. All authors have revised the paper critically and approved the final version.

Funding The Danish National Research Foundation (DNRF) supported he establishment of Research Center for Vitamins and Vaccines [DNRF108]. AR was supported by an unrestricted Faculty of Health Sciences-scholarship from University of Southern Denmark. SS was supported by a grant from the Danish Council for Independent Research [DFF - 4183-00316].

Competing interests None declared.

Patient consent for publication Not required.

Ethics approval Our study is based on published results from 3 original research papers. The study by da Silva et al. was approved by the GuineaBissau Government Ethics Committee and the Danish Central Scientific Ethics Committee. The study by van Tienen was approved by the Gambia Government/ MRC Laboratories Joint Ethics Committee and by the Ministry of Health of GuineaBissau. The study by Olesen et al. was approved by the National Research Ethics Committee in Guinea-Bissau and received consultative approval from the National Research Ethics Committee of Denmark.

Provenance and peer review Not commissioned; externally peer reviewed.

Data availability statement Information about HIV-1 was extracted from published results from original research papers carried out in parallel both in Bissau (1987, 1996, 2006 [da Silva et al], 2016 [0lesen et al.]) and Caió (1990, 1997, 2007 [van Tienen et al.) in Guinea-Bissau. Information about smallpox vaccination was based on data from a cohort of individuals, who had both participated in a smallpox vaccination scar survey (2005-2007) and an HIV prevalence survey (2004-2006) conducted in Bissau. The Bandim Health Project (bandim@ssi.dk) can be contacted for data requests.

Open access This is an open access article distributed in accordance with the Creative Commons Attribution Non Commercial (CC BY-NC 4.0) license, which permits others to distribute, remix, adapt, build upon this work non-commercially, and license their derivative works on different terms, provided the original work is properly cited, appropriate credit is given, any changes made indicated, and the use is non-commercial. See: http://creativecommons.org/licenses/by-nc/4.0/.

\section{ORCID iDs}

Marie Villumsen http://orcid.org/0000-0001-8454-4686
Christine Benn http://orcid.org/0000-0001-6102-3810

\section{REFERENCES}

1 Mayr A. Taking advantage of the positive side-effects of smallpox vaccination. J Vet Med B Infect Dis Vet Public Health 2004;51:199-201.

2 Weinstein RS, Weinstein MM, Alibek K, et al. Significantly reduced CCR5-tropic HIV-1 replication in vitro in cells from subjects previously immunized with vaccinia virus. BMC Immunol 2010;11:23.

3 Rieckmann A, Villumsen M, Jensen ML, et al. The effect of smallpox and BCG vaccination on the risk of HIV-1 infection in Guinea-Bissau and Denmark. Open Forum Infect Dis 2017;4.

4 da Silva ZJ, Oliveira I, Andersen A, et al. Changes in prevalence and incidence of HIV-1, HIV-2 and dual infections in urban areas of Bissau, Guinea-Bissau: is HIV-2 disappearing? AIDS 2008;22:1195-202.

5 Tienen Cvan, van der Loeff MS, Zaman SMA, et al. Two distinct epidemics: the rise of HIV-1 and decline of HIV-2 infection between 1990 and 2007 in rural Guinea-Bissau. J Acquir Immune Defic Syndr 2010;53:640-7.

6 Rieckmann A, Villumsen M, Jensen ML, et al. The effect of smallpox and Bacillus Calmette-Guérin vaccination on the risk of human immunodeficiency virus-1 infection in Guinea-Bissau and Denmark. Open Forum Infect Dis 2017;4.

7 Aaby P, Gustafson P, Roth A, et al. Vaccinia scars associated with better survival for adults. An observational study from GuineaBissau. Vaccine 2006;24:5718-25.

8 Jensen ML, Dave S, van der Loeff MS, et al. Vaccinia scars associated with improved survival among adults in rural GuineaBissau. PLoS One 2006;1:e101.

9 Olesen JS, Jespersen S, da Silva ZJ, et al. Hiv-2 continues to decrease, whereas HIV-1 is stabilizing in Guinea-Bissau. AIDS 2018;32:1193-8.

10 Månsson F. Hiv-1, HIV-2, and other sexually transmitted infections in GuineaBissau, West Africa. Lund University, 2012.

11 Maman D, Chilima B, Masiku C, et al. Closer to 90-90-90. The cascade of care after 10 years of art scale-up in rural Malawi: a population study. J Int AIDS Soc 2016;19:20673.

12 Chanda-Kapata P, Kapata N, Klinkenberg E, et al. The adult prevalence of HIV in Zambia: results from a population based mobile testing survey conducted in 2013-2014. AIDS Res Ther 2016;13:4.

13 de Oliveira T, Kharsany ABM, Gräf T, et al. Transmission networks and risk of HIV infection in KwaZulu-Natal, South Africa: a community-wide phylogenetic study. The Lancet HIV 2017;4:e41-50.

14 Quinn TC, Overbaugh J. Hiv/Aids in women: an expanding epidemic. Science 2005;308:1582-3.

15 Hegdahl HK, Fylkesnes KM, Sandøy IF. Sex differences in HIV prevalence persist over time: evidence from 18 countries in subSaharan Africa. PLoS One 2016;11:e0148502.

16 Jespersen S, Hønge BL, Oliveira I, et al. Challenges facing HIV treatment in Guinea-Bissau: the benefits of international research collaborations. Bull World Health Organ 2014;92:909-14.

17 Høgsborg M, Aaby P. Sexual relations, use of condoms and perceptions of AIDS in an urban area of Guinea-Bissau with a high prevalence of HIV-2. Sexual behaviour and networking: anthropological and socio-cultural studies on the transmission of HIV, edited by Tim Dyson Liege, Belgium, Editions Derouaux-Ordina, [1992] 1992:203-31.

18 Dean M, Carrington M, Winkler C, et al. Genetic restriction of HIV-1 infection and progression to AIDS by a deletion allele of the CKR5 structural gene. hemophilia growth and development study, multicenter AIDS cohort study, multicenter hemophilia cohort study, San Francisco City cohort, alive study. Science 1996;273:1856-62.

19 Beck KB, Hønge BL, Olesen JS, et al. Long-Term effects of smallpox vaccination on expression of the HIV-1 co-receptor CCR5 in women. PLoS One 2018;13:e0207259.

20 Netea MG, Joosten LAB, Latz E, et al. Trained immunity: a program of innate immune memory in health and disease. Science 2016;352:aaf1098.

21 Rice AD, Adams MM, Lindsey SF, et al. Protective properties of vaccinia virus-based vaccines: skin scarification promotes a nonspecific immune response that protects against orthopoxvirus disease. J Virol 2014;88:7753-63.

22 Jiang X, Clark RA, Liu L, et al. Skin infection generates non-migratory memory CD8+ TRM cells providing global skin immunity. Nature 2012;483:227-31.

23 Blok BA, Jensen KJ, Aaby P, et al. Opposite effects of vaccinia and modified vaccinia Ankara on trained immunity. Eur J Clin Microbiol Infect Dis 2019;38:449-56. 